\title{
Blended Learning Through an Interactive Mobile Application for Teaching Autistic Kindergarten Students
}

\author{
Mohammed J. Yousif ${ }^{* 1}$, Zahraa I. Al-Baloushi², Raqda H. Al-Dhahouri², Zamzam H. Al-Gufail², \\ and Ashgan S. Al-Nofli ${ }^{2}$ \\ ${ }^{1}$ Faculty of Science, Computer Science Department, Memorial University of Newfoundland \\ ${ }^{2}$ Faculty of Computing \& Information Technology, Sohar University, Oman. \\ * Corresponding author: Mohammed J. Yousif1, mohyou200210@gmail.com
}

\begin{abstract}
The mobile applications industry has had significant growth in the last few years. Mobile phones are everywhere since we use them in every part of our daily lives for entertainment, communication and other various uses. Unfortunately, there was also a substantial increase the number of autism cases in kids around the world, which has prompted for a dire need of a therapy method that is cheap, reliable and accessible for everyone who needs it. Researchers have tried several methods, like robotics and virtual reality, to help in the therapy of autistic children. While their results were promising, these technologies are still out of reach of most users due to their high cost. Mobile phones, however, are much more accessible since everyone has one, and they have a wide array of useful gadgets that can be used in making the therapy sessions more engaging and fun such as cameras, accelerometers, speakers, microphones and others. This project aims to design and implement an interactive learning environment based on a mobile application for teaching kids with special needs.
\end{abstract}

Keywords: Blended Learning; Mobile Application; Teaching Autistic Children; Interactive Learning. 


\section{Introduction}

Mobile applications as an industry have exploded in popularity in the last decade. As mobile phones continued to improve in terms of performance as well as price, so did their adoption among the average user (AbdulMalik \& Yousif, 2021). The ever-increasing userbase and ever-expanding tools for application development were a great incentive for programmers to develop software for mobile phones. Because of mobile phones' ease of use and accessibility, the general public have come to rely on their phones for a lot of tasks, including communication, banking, and entertainment among other tasks (Abusham \& Zaabi, 2021; Al-Balushi et al., 2018). This cycle of growth in terms of userbase and application development allowed the mobile application industry to balloon into the behemoth that it is today. According to "Statista", the mobile applications industry has accumulated 693 billion dollars in revenue in 2021, with estimated values of 809 and 935 billion dollars in revenue for the years 2022 and 2023 respectively (Statista, 2018). This can be seen in Figure 1.

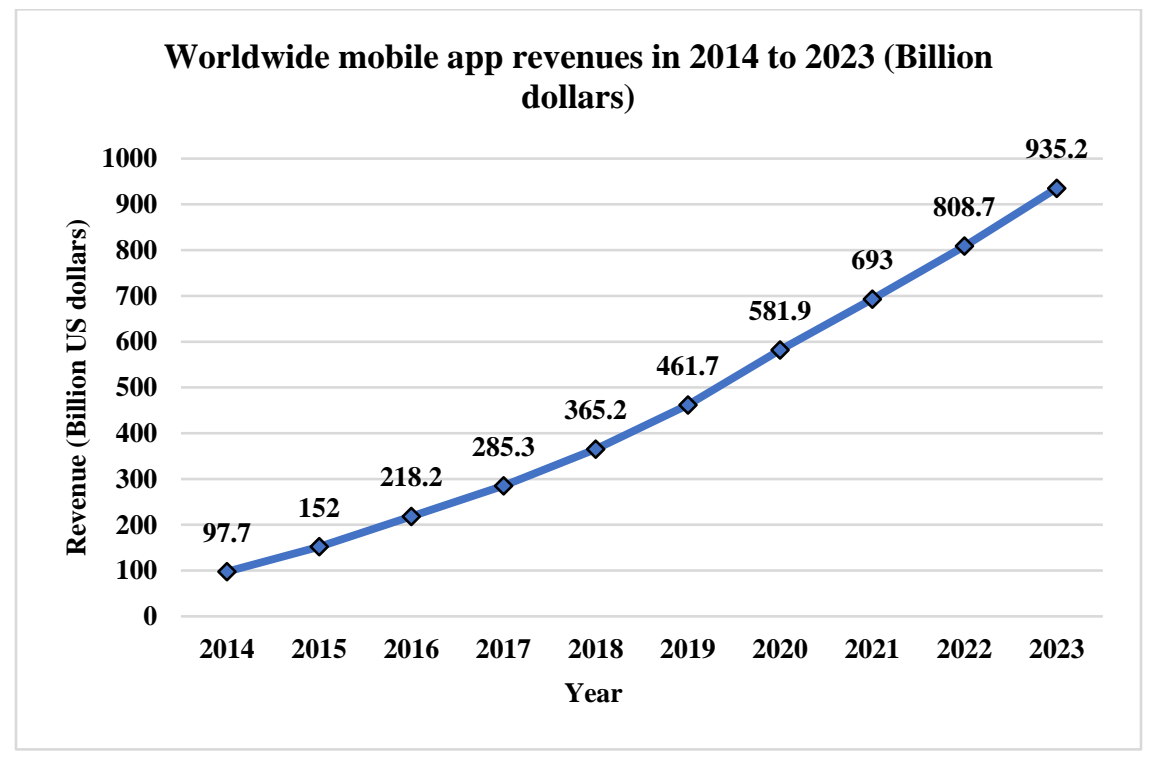

Figure 1: Worldwide mobile app revenues in 2014 to 2023 (Billion dollars)

Researchers have tried various technologies for implementing teaching methods, such as robotics and virtual/ augmented reality. While the results were promising (Yousif, M., 2021), due to their cost as well as limited availability, these technologies are not accessible enough for the general public nor easy enough to do develop programs for to encourage widespread adoption. Mobile phones, however, are the perfect solution for this problem. According to "Statista", 270 million people in the USA alone have smartphones, which is $82.3 \%$ of the entire population. Other countries like China and India have 912 million and 439 million smartphone users respectively (Statista, 2021). This 
can be seen in Figure 2. These results show that the mobile phone platform is very accessible and the perfect target for educational app development. Mobile phones have a large array of equipment for use in applications, such as cameras (for augmented reality), microphones, responsive touchscreens, IR blasters, gyroscopes, accelerometers, and many others that can all be used to make the applications more interactive and engaging. With this in mind, an application can be built to teach autistic children virtually anything, such as teaching them how to walk, read, pray, socialize with people and understand speech in multiple languages through the use of images, sound videos and a multitude of input methods (Yousif, 2021; Yousif et al., 2018). The use of mobile applications in research is not a new idea; many researchers have used mobile applications in many fields, including construction, design and education.

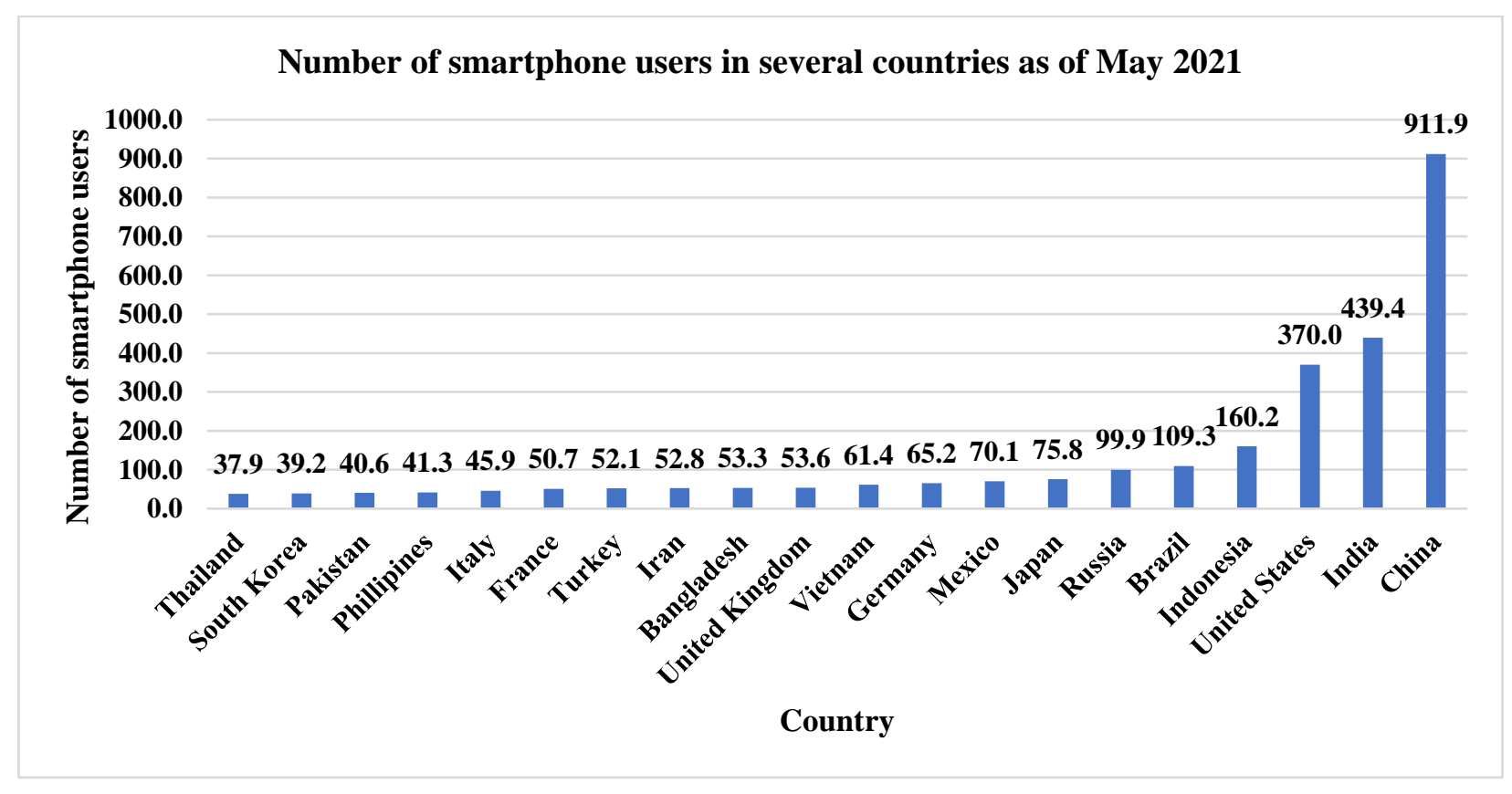

Figure 2: Number of smartphone users in several countries as of May 2021(Statista, 2021)

Autism is a neurological disorder that typically develops when a person is born, or at a very young age (Yousif et al., 2019). People with autism's main characteristics lie on a spectrum and vary in severity, but usually, they include difficulty when socializing, communicating, speaking, forming relationships and doing repetitive tasks. While many parts of the brain are usually affected by autism, the cerebellum is usually the one that is always abnormal in people with autism, both functionally and neurologically (Valnegri, P. et al., 2017). The number of people with autism is steadily increasing, from 6 in 1000 children in the year 200 to 19 per 1000 children in 2016 (CDC, 2016). Mobile applications are perfect for helping children with autism, because they can be catered specifically to their needs and they have a range of tools to help increase engagement and accessibility. Mobile phones' built-in equipment can also 
allow for the monitoring of the children with autism so that a retrospective report can be built for each child without them feeling like they are being intruded upon. This can allow the researchers to follow the child's improvement both in terms of emotional and academic performance without causing any distress for the child.

Cloud Computing techniques offer access to various capabilities such as teaching and learning software and services on demand and pay the use services on a monthly or yearly basis (AL-Balushi et al., 2017; Al-Shezawi et al., 2017; Yousif \& Alattar, 2017; Saini et al., 2011).

The aim of this paper is to develop a comprehensive and informative mobile application to educate autistic children and help them to respond better to commands. It will cover a wide variety of topics, including learning Quran, sport activities, parts of the body, numbers, letters and colors.

\section{Problem Statement and Objectives}

Statistics indicate that the frequency of children with autism in the Sultanate of Oman is about 2 per 1000 children, with the highest regional number of cases being in Muscat, where there were 36 per 10000 children with autism. It was also show that males were 3.4 times as likely to have autism than females and these numbers are 15 times higher than they were in 2011 (Al-Mamri et al., 2019). Just like in other countries like the USA and the UK, autism cases are rapidly increasing, which means a cheap and effective therapy method needs to be found as soon as possible. Currently, therapy methods that are used in clinics are very time consuming, take a lot of work and are generally not as easily accessible. Other researchers have tried to use new technologies like robotics (NAO, KASPAR, Pepper etc.) and virtual/ augmented reality solutions. The results displayed were very promising; the children showed increased engagement as well improved socializing abilities (Yousif, M., 2021). Unfortunately, since these technologies are very new, they are quite expensive and as a result, not as easily accessible to most people. Mobile phones, however, are much more accessible. Most people these days have one since it is vital for communication, entertainment as well as other important tasks. They also have a wide range of equipment for use in the application like cameras, microphones, gyroscopes and accelerometers. This project aims to design and implement a mobile phone application that can teach autistic children a variety of predetermined teaching materials like the Quran, sport activities, parts of the body, numbers, letters and colors.

\section{Research Methodology}


This paper deploys an experimental method in developing an interactive mobile application to teach children with autism. The project focuses on a more hands on approach to teaching like games and learning by example because children are usually much more engaged during the lessons when they are playing and having fun. Features like video, audio and touch interaction were incorporated to help keep the student's attention. Other features could be incorporated like the gyroscope and accelerometer in a future version of the app for even more intractability. The interactive learning environment's framework is built upon three important pieces, which can be seen in Figure 3, that work together to provide an adequate learning experience. Firstly, a literature survey was performed to have a basic idea of all of the methods that are successful with teaching autistic children and to improve on any weaker aspects of the medium. Then, a mobile application has been written in the Kotlin language with a backend that is easily customizable and upgradable to house the learning materials. Finally, a few subjects were studied to create the learning materials that will then be implemented in the mobile application. A mobile application was chosen because mobile phones are very popular with children, and the application can quickly be customized to the student's need due to its high flexibility and access to a large array of input methods. The data that was collected during the experiments was qualitative and the quantitative aspect was ignored. This is because the interaction with the participants was very brief (over a short period of time) and the quantitative data that was gathered was not accurate enough and was not a good representation of over time improvement. The characteristics that were most focused upon during the experiment were the students' engagement, happiness and information retention.

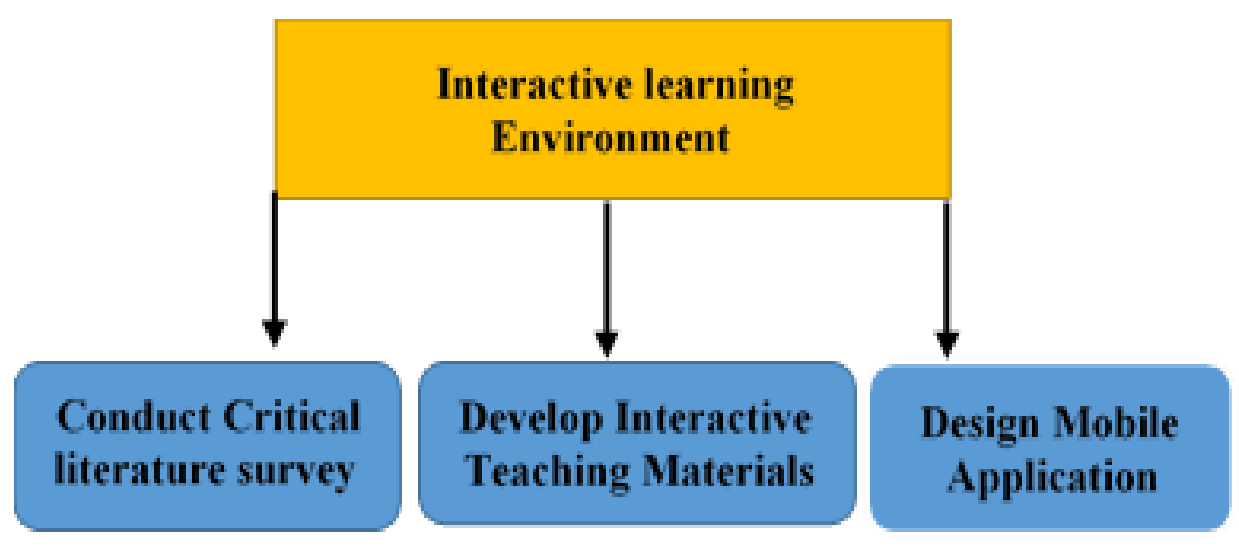

Figure 3: Interactive learning environment framework

\section{Literature Survey}


Many researchers have discussed and proposed a solution to teach and educate autistic children based on the implementation of different methods.

Eder, M. et al. conducted a study that focuses on helping people with autism in learning through eye catching graphics. The results show that the 15 years and below students are more interested in the game than the traditional methods of teaching. However, the students of 18 years old and above, did not have long attention span when interacting with the game (Eder et al., 2016). Tashnim, A. et al. conducted a related study of research that showed that over $25 \%$ of children with autism spectrum disorder (ASD) generally need non-verbal aid which shows that the computer interacting activities makes it easier for these children to learn and understand more efficiently (Tashnim et al., 2017). Dehkordi, S. et al. conducted a study that includes six children with ASD (5 boys and 1 girl). The results indicated that $41.4 \%$ of the children spend their free time playing video games, which translated well during their testing with the therapy application (Dehkordi, S. R. et al., 2014). De Urturi et al. showed that $70 \%$ of the children were engaging well with the designed activities given by the parents. The remaining $30 \%$ were able to adapt to the original designed activities (De Urturi et al., 2011). Soomro, N., \& Soomro, S. stated that the app provided a better learning environment for autistic students. Almost $70 \%$ of them were satisfied with the app. The app was found to facilitate the communication and instinctive abilities for children with autism (Soomro, N., \& Soomro, S., 2018). A report by Aburukba, R. et al. shows that more than $80 \%$ of children have mobile phones, and the designed app aims at monitoring these children and educating them through a gaming package in the app which allow teachers and parents to keep track of the children. The tested group in were children age $12 \& 14$ (Aburukba, R. et al., 2017). Wojciechowski, A., \& Al-Musawi, R. showed that 50\% of people diagnosed with ASD in preschool would have a rough adulthood. On the other hand, people with early signs of ASD who happen to have a good adult life were only around 4 to 12\% (Wojciechowski, A., \& Al-Musawi, R., 2017). Fage, C. et al. conducted research around the outcome of the socio-cognitive Remediation applications and have shown that $80 \%$ of the participants have had successful trials, and were able to move to more challenging levels (Fage, C. et al., 2018). Chia, G. et al. used an application that managed to reach $70 \%$ of engagement in 33 families who have a child with autism in their study. The results showed that the app was being used for 4-6 hours per week which shows a great engagement from the families and their children (Chia, G. et al., 2018). Martín, F. C. E. has shown in his report a magnificent increase in the social behavior of children with ASD, as it has increased up to 52\%, and reduced their social missteps by 56\% (Martín, F. C. E., 2018). Simmons, E. S. et al. conducted a study around the measurement of mobile application effectiveness in enhancing the 
speech and level of understanding languages. The study included 40 students aged 5-19 years old. It has shown an increase of $60 \%$ in developing the flow of speech and language understanding (Simmons, E. S. et al., 2016). Egger, H. L. et al. used a method that aims at measuring the reaction of children with autism while watching videos. The results showed that $46 \%$ viewed 4 movies, 9.5\% viewed 3 movies, $15.7 \%$ viewed 2 movies, $8.9 \%$ viewed 1 movie, and $19.9 \%$ viewed no movies (Egger, H. L. et al., 2018). Sung, A. N. et al. designed an app that provides different assistance methods for ASD children in terms of improving their facial recognition and social interaction. The app showed 70\% improvement of the targeted children age 6-10 years old (Sung, A. N. et al., 2015). Kim, J. W. et al. discussed some of the effective apps that were designed to assist children with ASD. The study showed that out of a total of 695 apps, only $4.9 \%$ are apps are targeting and helping children with autism. On the contrary, $95.1 \%$ showed no signs of directly impacting the children (Kim, J. W. et al., 2018). Rodríguez-Fórtiz, M. J. et al. conducted a study around the learning support platform (picaa) activities, and has shown that ASD children have increased their engagement levels by 30\% after using the app (Rodríguez-Fórtiz, M. J. et al., 2011). Vlachou, J. A., \& Drigas, A. S. conducted a study around the use of educational apps by 6 people with ASD, aged 6-20 years old and has shown that the time spent at commination apps were 51\%, academic apps were 36\%, and gaming apps were $13 \%$ (Vlachou, J. A., \& Drigas, A. S., 2017). Fletcher-Watson, S. et al. started a study that took place in an area where support for children with ASD was minimal (around 54\% support). After utilizing supportive apps, the children have reached over 90\% of support (Fletcher-Watson, S. et al., 2016) . Khan, A. et al. designed an app as a part of a study that was aiming at developing the interaction of ASD children through positive and negative reactions when using the app. The results have shown that $70 \%$ of the children have reactive positively and $30 \%$ reacted negatively (Khan, A. et al., 2018). Devecchi, C. et al. focused on supporting ASD children aged 11-16 years old with their social and management skills. Teachers have witnessed over $60 \%$ improvement in the children's level in class, and parents were impressed with their children's behavior (Devecchi, C. et al., 2009). Skillen, K. L. et al. designed an app that targeted autistic people and had 20 participants aged 11-18. The feedback given by the parents in using the app shows $70 \%$ of the children use it every day, and the other $30 \%$ only use it when necessary (Skillen, K. L. et al., 2016). Mangafa, C. et al. studied the engagement of ASD children in the Joint Attention (JA), where schools can use iPads to reward students to learn. The results are; $20 \%$ of the parents agreed with the method used, and $80 \%$ preferred that their children interact more in the social life rather than the iPad (Mangafa, C. et al., 2016). Alhajeri, O. et al. conducted a study on 40 participants, aged 
3-17 years old. The app aims to enhance the communication and learning of ASD students. The study met $90 \%$ of the quality indicators (Alhajeri, O. et al., 2017).

\section{Implementation}

To build a mobile application, a suitable programming language as well as a reliable IDE (integrated development environment) needs to be chosen. For the paper's use case, Kotlin was chosen as the programming language because it is backwards compatible with most Java libraries and requires less code to achieve the same purpose. As for the IDE, android studio was chosen because it has great support for Kotlin and it is the gold standard for android development. It also allows for quick previews of the application and has great support for multilingual applications. A database is also required for storing all of the data of the students, so Wampserver 64 was used. The application is made up of several different components that all work together to provide the user with a suitable learning experience. The entire program was built with two languages in mind, English and Arabic, so that both local people as well as international students can use it (Yousif, 2013). The first screen that the user is presented with is the login screen, which can help the user get access to their information and appropriate functions, depending on whether they are a user, an admin or a guest. If the user does not currently have an account, they can make one in the registration page by inputting in their email, name, phone number and preferred password. This can be seen in Figure 4.

The second screen contains all of the functions that are available to each type of user. If they are a user, they are taken to another screen that provides them with three choices; Entertainment, Learning and Testing (Yousif et al., 2011). The entertainment section allows the user to play simple games that also have an educative value to them. The learning section gives the user access to all of the available learning material, which have a wide variety, including academic topics like fruits, numbers, alphabet, and religious topics like learning to pray and reading the Quran. The final section, the testing section, gives the user a range of quizzes to take so that they can test the new knowledge that they learnt in the reading section. They also have access to their scores from tests they have previously taken so they can gauge how well they did and find out which subjects they are weak in. All of this can be seen in Figure 5.

If they are an admin, however, they have access to other functions like viewing all student scores, being able to alter and/ or remove information and have useful data like averages and standard deviations calculated when needed. The final type of user is guest, which only has access to a basic description of the application, a list of the available learning material as well as the contact info of the programmers and none of the functions that are available to the user and the admin. All of this can be seen in the case diagram of the application system in Figure 6 . 

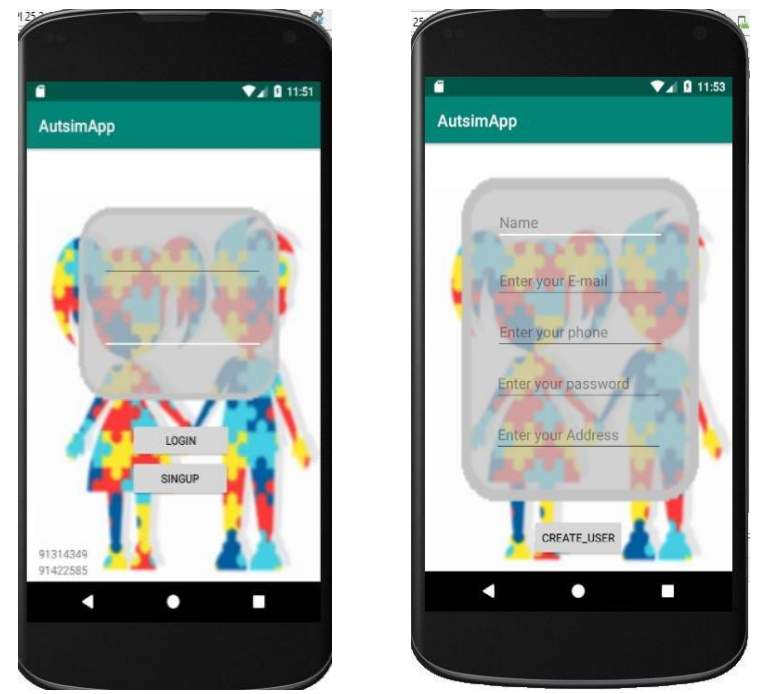

Figure 4: Login and registration form
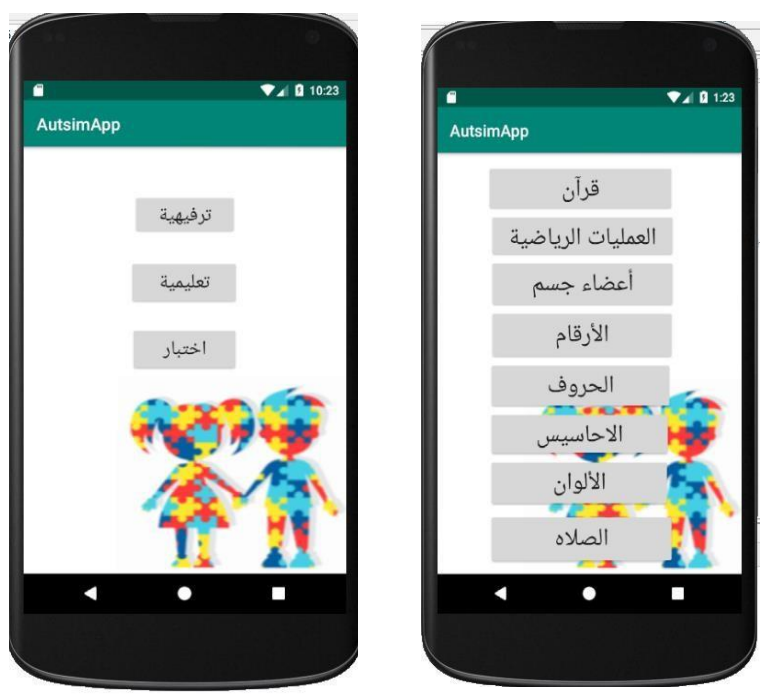

Figure 5: The menus that the user has access to

A case diagram can be used to provide a graphical representation of the connection between the different types of actors. Actors are people who play an interactive role within the system, such as admin, a user, and a guest. Each different actor has access to a completely different set of functions, depending on their use case.

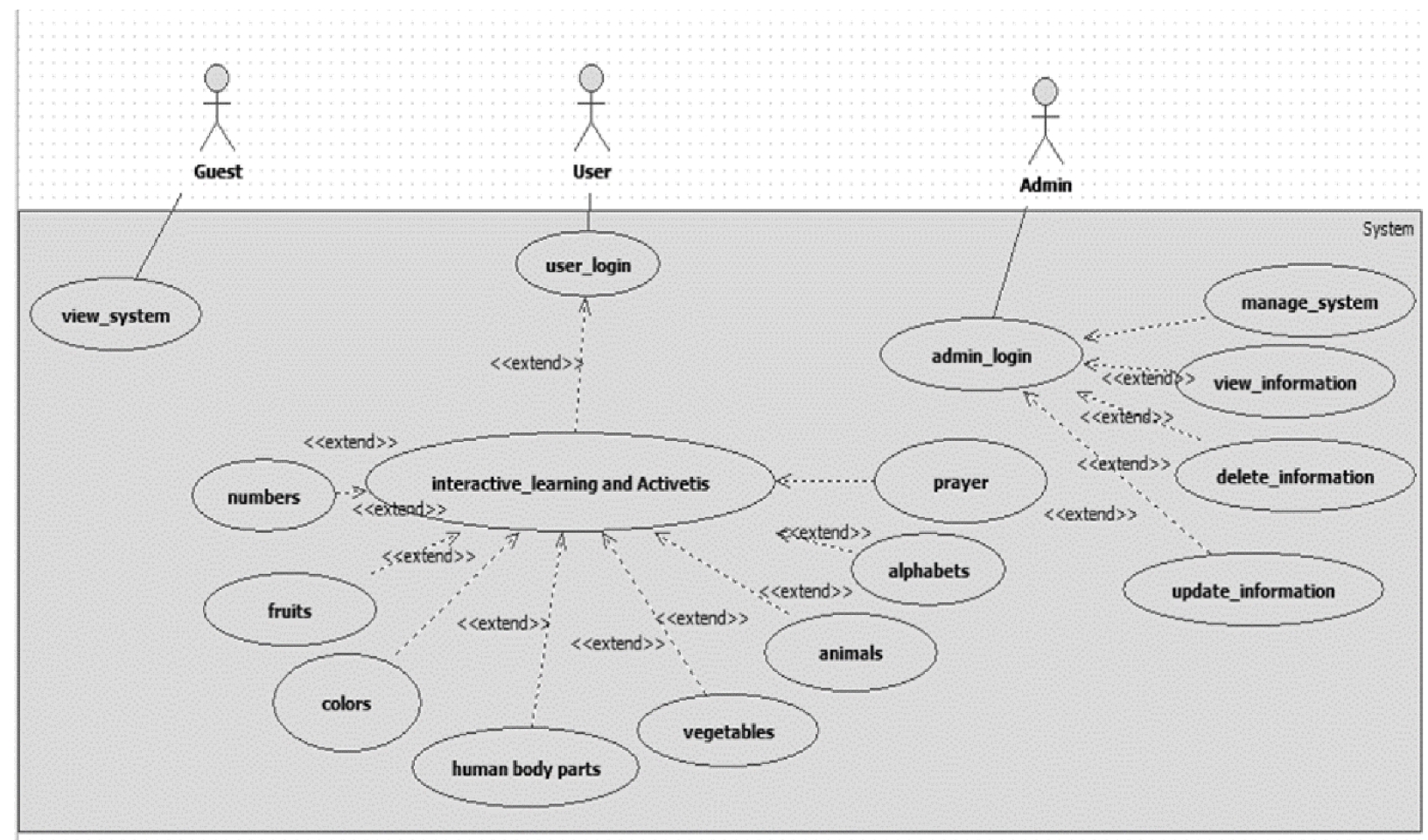

Figure 6: Use case diagram 
Figure 7 demonstrates all of the religious learning materials. The students are taught verses from the Quran and they are also taught all stages of praying. An audio player is used to recite all of the verses and it has all of the important features like pausing, resuming and scrubbing through the timeline. A video of a person praying can also be played just in case images and text is not enough. Figure 8 demonstrates all of the body and emotion related materials. Here, the student is taught about parts of the body and the most common emotions that are usually exhibited by people. Emotional education is especially important because autistic children usually have difficulty expressing and interpreting emotions.

Figure 9 demonstrates all of the mathematical related activities. The students are taught all of the basic number (from 1 through 10) and they are taught all of the basic operators, which include multiplication, addition, subtraction and division. Students are also taught how to count by showing them a random number of objects and their number underneath. Figure 10 demonstrates all of the colour and alphabets related activities. The students are taught all of the alphabets as well as corresponding words that start with them. They are also taught the names of different colours as well. The application, however, is not limited to these learning activities and can be expanded and catered to the student's needs.

\section{Results}

All of the participants that took part in this experiment were from the Oman Science Festival On that took place on the 8th of November 2019, in Muscat. They were all aged 4-6, with an average age of 5, and there were 50 total participants. There were also 3 times more males than there were females. All of the children consented to take part in this survey and their legal guardians/ parents were informed of the experiments that will take place, all of whom agreed with the terms. Throughout the entire experiment, the children were very immersed in the mobile application. We asked their legal guardians/parents if they noticed any differences in their behaviour, and we were told that there was a substantial shift in emotional and social engagement compared to when they were at home or at a treatment clinic. Out of the 50 children, 40 of them were very happy during the experiments, 5 of them hated the experiment and 5 of them showed no changes in attitude throughout. The children were also interested in a greater variety of topics and were learning them at much faster rates than usual because a mobile application makes the learning aspect more fun and interesting. By the end, the mobile application had a significant positive impact on the students mental, social and emotional abilities (Yousif, 2015). They were also much more talkative and were more willing to open up with their peers as well as other people around them. 

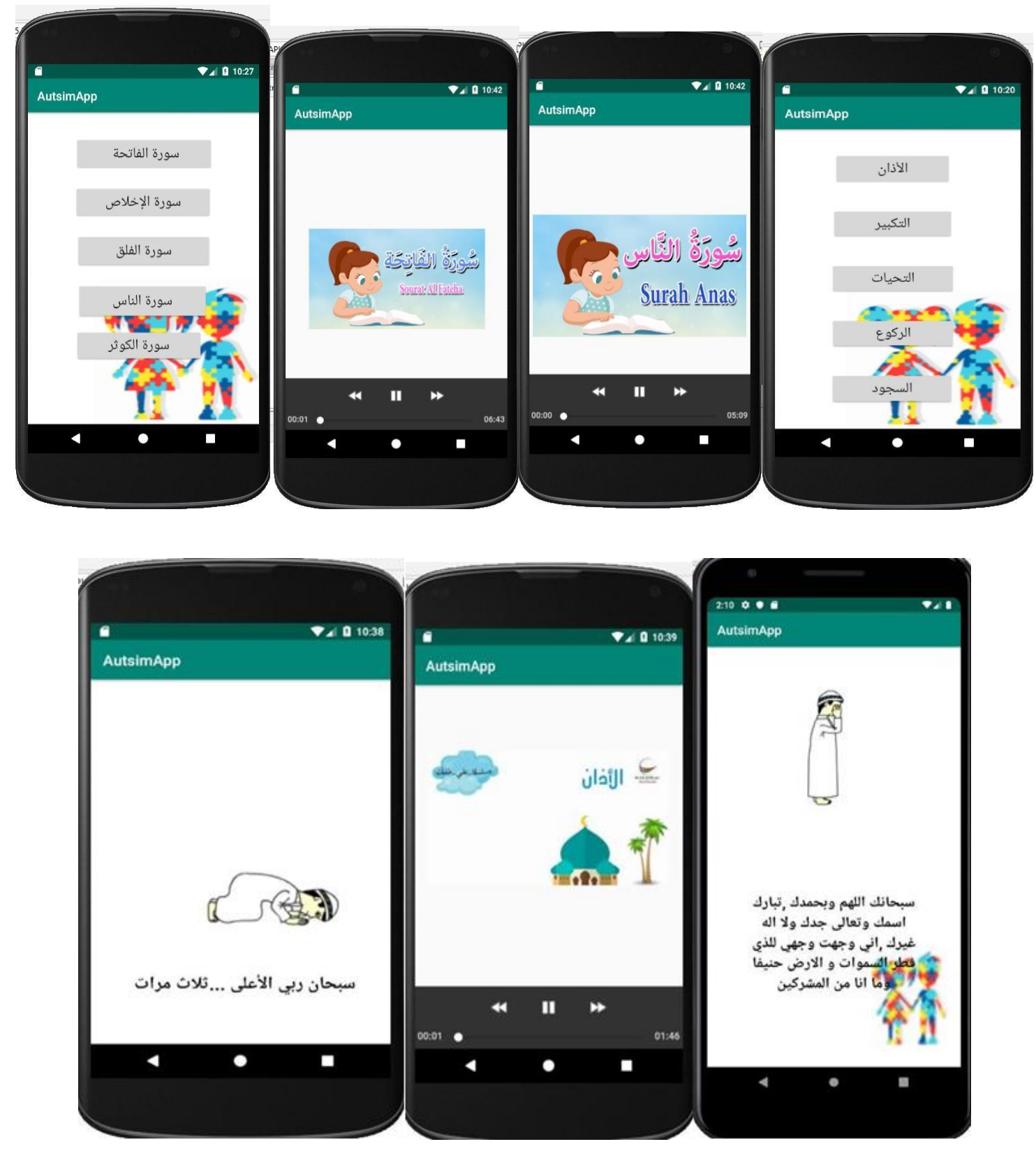

Figure 7: Religious related activities 

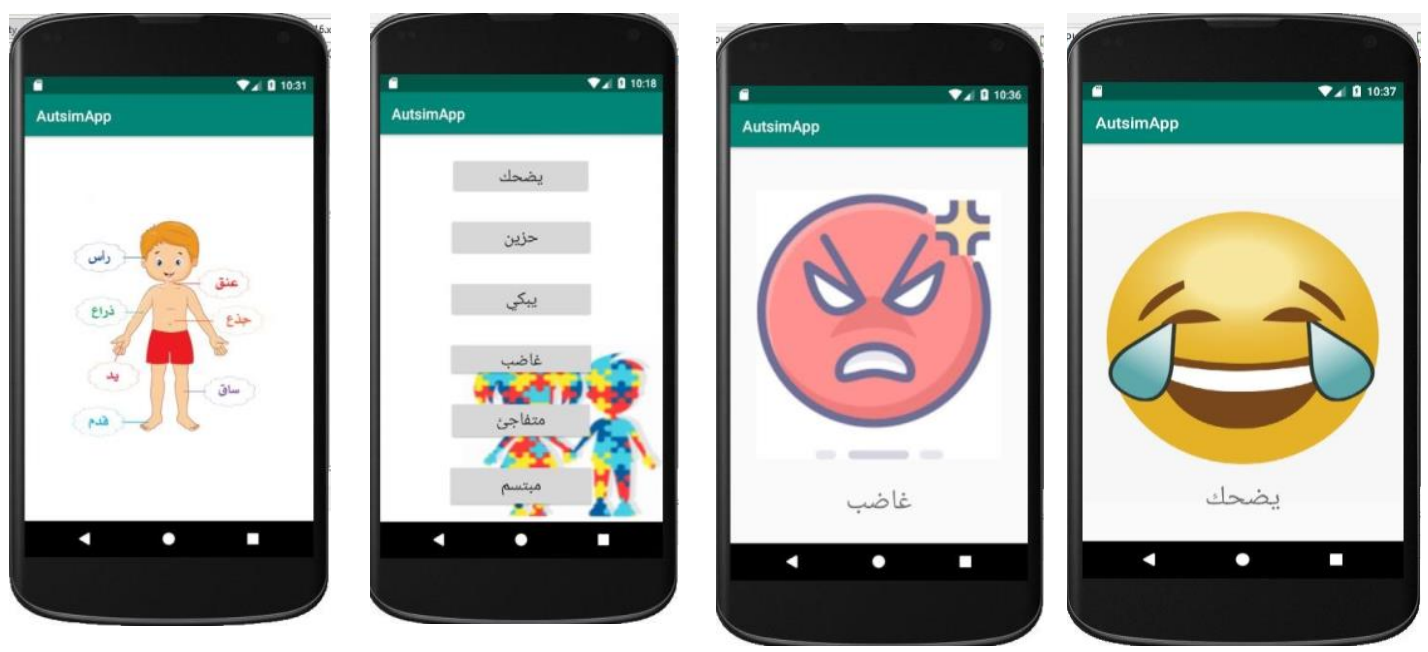

Figure 8. Body and emotion related activities
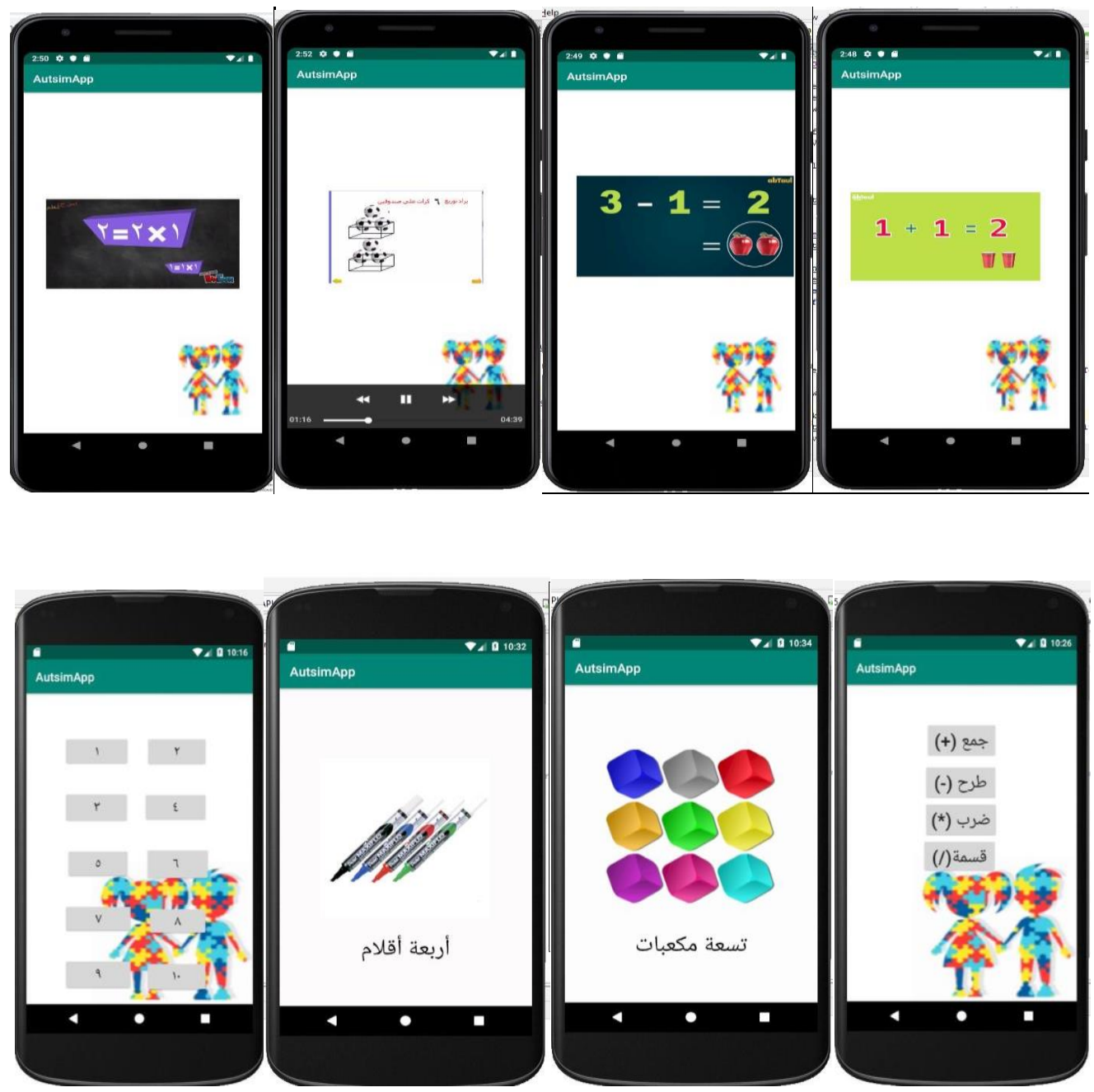

Figure 9: Mathematics related activities 

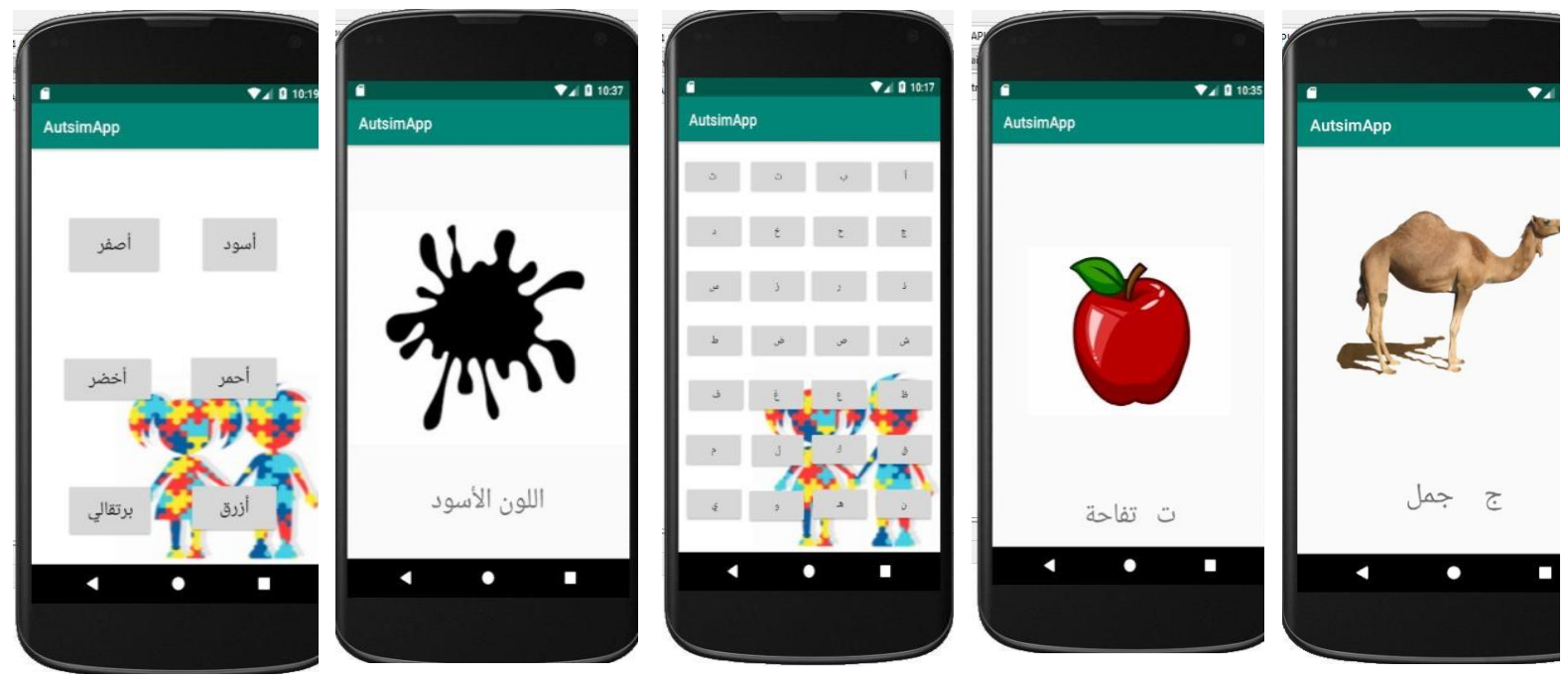

Figure 10: Colour and alphabet related activities

\section{Conclusion}

The number of cases of autism around the world are gradually increasing, up to a staggering 19 per 1000 children in the year 2016 (CDC, 2016). The same is true in Oman, where the number of autism cases has increased 15-fold (to 2 per 1000 children) than they were in 2011 (Al-Mamri et al., 2019). Due to these concerning numbers, many researchers around the world started to look for a cheap and efficient therapy method to help with the increasing cases. This paper aims to tackle this issue using a mobile application that was designed to help educate and teach autistic children. Our results were very promising; the children were incredibly immersed during the activities and were much more playful and talkative when interacting with their peers and the adults. This is because the mobile application was very simple, so it didn't overload their senses and the learning material had videos, audio and lots of input methods so the students continued to be engaged. The children were also more interested in a greater variety of subjects. Compared to other papers that used other methods such as virtual/ augmented reality and robotics (Yousif, M., 2021; Yousif, J., 2020; Yousif, M., 2021), the improvements were comparable and the method used to achieve them (mobile application) is much cheaper and much more accessible to most people.

\section{Acknowledgment}

The research leading to these results has received no Research Project Grant Funding. 


\section{References}

[1]. Al-Balushi, H. A., Yousif, J. H., \& Kazem, H. A. (2018). Mobile Application for Visualizing Weather Data in Oman Based Cloud Computing. International Journal of Computation and Applied Sciences IJOCAAS, 4(1).

[2]. AL-Balushi, A. I., Yousif, J., \& Al-Shezawi, M. (2017). Car accident notification based on Mobile cloud computing. International Journal of Computation and Applied Sciences IJOCAAS, Volume 2, (2).

[3]. AbdulMalik, A. H. H., \& Yousif, M. J. (2021). Smart Online Grocery Shopping App Development. Artificial Intelligence \& Robotics Development Journal, 93-102.

[4]. Abusham, E. A., \& Zaabi, A. M. A. (2021). Smartphone application for Self-Management Diabetes: A review. Applied computing Journal, 25-37.

[5]. Aburukba, R., Aloul, F., Mahmoud, A., Kamili, K., \& Ajmal, S. (2017, October). AutiAid: A learning mobile application for autistic children. In 2017 IEEE 19th International Conference on e-Health Networking, Applications and Services (Healthcom) (pp. 1-6). IEEE.

[6]. Alhajeri, O., Anderson, J. A., \& Alant, E. (2017). Effectiveness of the use of iPads to enhance communication and learning for students with autism: A systematic review. International Journal of Technology and Inclusive Education (IJTIE), 6 (1), 1041-1055.

[7]. Al-Mamri, W., Idris, A. B., Dakak, S., Al-Shekaili, M., Al-Harthi, Z., Alnaamani, A. M., ... \& Islam, M. M. (2019). Revisiting the prevalence of autism spectrum disorder among Omani children: a multicentre study. Sultan Qaboos University Medical Journal, 19(4), e305.

[8]. Al-Shezawi, M. O., Yousif, J. H., \& AL-Balushi, I. A. (2017). Automatic attendance registration system based mobile cloud computing. International Journal of Computation and Applied Sciences, 2(3), 116-122.

[9]. CDC, (2016). Accessed 7/15/2021, https://www.cdc.gov/ncbddd/autism/data.html.

[10].Chia, G. L. C., Anderson, A., \& McLean, L. A. (2018). Use of technology to support self-management in individuals with Autism: Systematic Review. Review Journal of Autism and developmental disorders, 5(2), 142-155.

[11].Dehkordi, S. R., \& Rias, R. M. (2014, September). Using mobile game application to teach children with Autism Spectrum Disorder (ASD) multiple cues responding: A pilot study. In 2014 3rd International Conference on User Science and Engineering (i-USEr) (pp. 216-220). IEEE.

[12]. Devecchi, C., Mintz, J., \& March, C. (2009, July). Supporting user participation in developing mobile technology to help young people with autism: the HANDS smartphone project. In International Conference on Information Communication Technologies in Education (ICICTE 2009).

[13].De Urturi, Z. S., Zorrilla, A. M., \& Zapirain, B. G. (2011, July). Serious Game based on first aid education for individuals with Autism Spectrum Disorder (ASD) using android mobile devices. In 2011 16th International Conference on Computer Games (CGAMES) (pp. 223-227). IEEE.

[14].Eder, M. S., Diaz, J. M. L., Madela, J. R. S., Marife, U., \& Sabellano, D. D. M. (2016). Fill Me App: An Interactive Mobile Game Application for Children with Autism. Int. J. Interact. Mob. Technol., 10(3), 59-63.

[15].Egger, H. L., Dawson, G., Hashemi, J., Carpenter, K. L., Espinosa, S., Campbell, K., ... \& Sapiro, G. (2018). Automatic emotion and attention analysis of young children at home: a ResearchKit autism feasibility study. NPJ digital medicine, 1(1), $1-10$.

[16].Fage, C., Consel, C. Y., Balland, E., Etchegoyhen, K., Amestoy, A., Bouvard, M., \& Sauzéon, H. (2018). Tablet apps to support first school inclusion of children with autism spectrum disorders (ASD) in mainstream classrooms: A pilot study. Frontiers in psychology, 9, 2020.

[17].Fletcher-Watson, S., Petrou, A., Scott-Barrett, J., Dicks, P., Graham, C., O’Hare, A., ... \& McConachie, H. (2016). A trial of an $\mathrm{Pad}^{\mathrm{TM}}$ intervention targeting social communication skills in children with autism. Autism, 20(7), 771-782.

[18].Kim, J. W., Nguyen, T. Q., Gipson, S. Y. M. T., Shin, A. L., \& Torous, J. (2018). Smartphone apps for autism spectrum disorder-Understanding the evidence. Journal of Technology in Behavioral Science, 3(1), 1-4.

[19]. Khan, A., Li, K., \& Madden, J. (2018). Mobile Aid to Assist with Care Decisions in Children with Autism Spectrum Disorder (ASD). Journal of healthcare engineering, 2018.

[20]. Mangafa, C., Moody, L., Woodcock, A., \& Woolner, A. (2016, July). The Design of Guidelines for Teachers and Parents in the Use of iPads to Support Children with Autism in the Development of Joint Attention Skills. In International Conference of Design, User Experience, and Usability (pp. 178-186). Springer, Cham.

[21]. Martín, F. C. E. (2018). Applications for mobile devices focused on support for autism spectrum disorder population and/or people in their immediate environment in their daily lives: a systematic and practical review from a Spanish-speaking perspective. arXiv preprint arXiv:1806.01041.

[22]. Rodríguez-Fórtiz, M. J., Fernández-López, A., \& Rodríguez, M. L. (2011). Mobile communication and learning applications for autistic people. Autism spectrum disorders: From genes to environment, 349-362.

[23]. Saini, S. L., Saini, D. K., Yousif, J. H., \& Khandage, S. V. (2011, July). Cloud computing and enterprise resource planning systems. In Proceedings of the world Congress on Engineering (Vol. 1, pp. 681-684).

[24]. Statista, (2021). Accessed 7/15/2021, https://www.statista.com/statistics/748053/worldwide-top-countries-smartphone-users/. [25].Statista, (2018). Accessed 7/15/2021, https://www.statista.com/statistics/269025/worldwide-mobile-app-revenue-forecast/

[26].Simmons, E. S., Paul, R., \& Shic, F. (2016). Brief report: A mobile application to treat prosodic deficits in autism spectrum disorder and other communication impairments: A pilot study. Journal of autism and developmental disorders, 46(1), 320327. 
[27].Skillen, K. L., Donnelly, M. P., Nugent, C. D., \& Booth, N. (2016). LifePal: a mobile self-management tool for supporting young people with autism. In XIV Mediterranean Conference on Medical and Biological Engineering and Computing 2016 (pp. 1174-1179). Springer, Cham.

[28].Soomro, N., \& Soomro, S. (2018). Autism Children's App using PECS. arXiv preprint arXiv:1801.03529.

[29].Sung, A. N., Bai, A., Bowen, J. G., Xu, B., Bartlett, L. M., Sanchez, J. C., ... \& Tanaka, J. W. (2015). From the small screen to the big world: mobile apps for teaching real-world face recognition to children with autism. Advanced Health Care Technologies, 1, 37-45.

[30].Tashnim, A., Nowshin, S., Akter, F., \& Das, A. K. (2017, October). Interactive interface design for learning numeracy and calculation for children with autism. In 2017 9th International Conference on Information Technology and Electrical Engineering (ICITEE) (pp. 1-6). IEEE.

[31]. Yousif, M. (2021). Viability of Robots in Improving Autistic Student's Engagement and Happiness When Learning. Artificial Intelligence \& Robotics Development Journal, 26-42.

[32]. Yousif, J. (2020). Humanoid Robot as Assistant Tutor for Autistic Children. International Journal of Computation and Applied Sciences, 8(2).

[33]. Yousif, M. (2021). Training and teaching applications for Autistic Children based on C\# standalone application. Artificial Intelligence \& Robotics Development Journal, 66-79.

[34]. Yousif, J. H. (2021). Social and Telepresence Robots a future of teaching. Artificial Intelligence \& Robotics Development Journal, 1(1), 58-65.

[35]. Yousif, J. H., Kazem, H. A., \& Chaichan, M. T. (2019). Evaluation implementation of humanoid robot for autistic children: a review. International Journal of Computation and Applied Sciences, 6(1), 412-420.

[36]. Yousif, J. H., Al-Hosini, M., Al-Sheyadi, S., Al-Ofui, A., \& Al-Sheyadi, M. (2018). Questionnaire of Using Humanoid Robot for Teaching and Learning Kids. International Journal of Computation and Applied Sciences (IJOCAAS), 4(2), 324-329.

[37]. Yousif, J. H., Saini, D. K., \& Uraibi, H. S. (2011, July). Artificial intelligence in e-leaning-pedagogical and cognitive aspects. In Proceedings of the World Congress on Engineering (Vol. 2, pp. 6-8).

[38]. Yousif, J. H. (2013). Natural language processing based soft computing techniques. International Journal of Computer Applications, 77(8).

[39]. Yousif, J. H. (2015). Classification of mental disorders figures based on soft computing methods. International Journal of Computer Applications, 117(2), 5-11.

[40]. Yousif, J. H., \& Alattar, N. N. (2017). Cloud management system based air quality. International Journal of Computation and Applied Sciences (IJOCAAS), 2(2).

[41]. Yousif, M. (2021). Humanoid Robot Enhancing Social and Communication Skills of Autistic Children. Artificial Intelligence \& Robotics Development Journal, 80-92.

[42]. Wojciechowski, A., \& Al-Musawi, R. (2017). Assisstive technology application for enhancing social and language skills of young children with autism. Multimedia Tools and Applications, 76(4), 5419-5439.

[43]. Valnegri, P., Huang, J., Yamada, T., Yang, Y., Mejia, L. A., Cho, H. Y., ... \& Bonni, A. (2017). RNF8/UBC13 ubiquitin signaling suppresses synapse formation in the mammalian brain. Nature communications, 8(1), 1-15.

[44]. Vlachou, J. A., \& Drigas, A. S. (2017). Mobile Technology for Students \& Adults with Autistic Spectrum Disorders (ASD). International Journal of Interactive Mobile Technologies, 11(1). 